a unit in unfamiliar territory and uncertain times, I quickly found a new respect for many healthcare settings and was impressed that members of the dental team were able to make a difference in so many ways. Seeing colleagues old and new, watching them amalgamate into new teams, growing personally and professionally I felt so proud but, on the flipside, watching them go through some of the hardest times they may have had to face or situations they would not have encountered if it wasn't for the pandemic. Tears of joy and pain alike were shared more with colleagues at times than with family.

During the time preceding the first lockdown, it was scary when the world was winding down and handing over all available PPE, calling for volunteers to make scrubs, not to mention the scramble for a roll of toilet paper: things we would normally take for granted. Patient clinics being cancelled was usually unheard of, limiting building footfall, cessation of aerosol generating procedures, new services such as emergency dental hubs... there was silence in the air and a lack of traffic jams. We waited for daily political updates, knowing that some areas of dentistry were having to close their dental doors to much cared-for patients. There was so much stopping but at the same time cogs were still turning behind the scenes to keep some sort of function. The reality hit hard as the number of COVID-19 cases and toll on life rose but somehow, as daunting as it was, we reacted. We were given passes to travel in lockdown and watched swabbing tents being set up in our car parking space at work. We learnt to manage a bucket load of feelings: worry, guilt, feeling upset and being 'proud' to work for the NHS! Phew, what a rollercoaster it was, and has been ever since, but we held on tight and rode in our own individual ways, be it Staying Home to Stay Safe or working.

\section{Scary moments, and juggling}

As a DCP, I have worked in many different settings but being present on a hospital ward with COVID positive patients, championing mouth care and assisting the health care assistants (HCAs) during the first lockdown, was a setting I never dreamt of experiencing. It was a fantastic opportunity to implement oral care in a different setting, although there were certainly some scary moments when helping provide personal care for a COVID positive patient. I worried about going home in the days before PCR testing and lateral flow kits and felt crazy for using antibacterial spray from head to toe in the car park before getting into my car. It still feels surreal.

The Friends and Family Test took on a new meaning as we were all some patients had when hospitals closed their doors to visitors. Digital technology has been a blessing during this time in many different ways and, although video calling brought a familiar face to the fingertips, I have discovered that this is no replacement for direct human interaction: a hug or a reassuring hand on a shoulder or offering a tissue to patients, family or colleagues, there simply is no substitute... and this is coming from a contact phobe!

It was apparent that for some, embarking on sharing the most challenging life experiences and becoming sources of support to some of the most vulnerable of our communities, cemented professional relationships. We were trying to juggle providing the best care for patients and doing the right thing for the public but at the same time having to protect our own families and neighbours were clapping when I feel it's all in a day's work; the kindness and donations, the impatience, the frustration of fighting a constant battle against the virus, resentment in those super sunny days. In hindsight, I perhaps should have been bolder when trying to juggle shift times to avoid standing in shopping queues; there was a fear of not wanting to flash my NHS ID badge for risk of tuts or judgement for jumping the queue.

I joined the swabbing team as part of the second wave response during the winter lockdown. I found myself working in settings including prison services, care homes and refuges. This has been interesting and carrying out a role in a body part I am more familiar was somewhat a relief. It was, at times, overwhelming to think that we were going into sites of outbreaks. We are so used to patients coming into our dental

\section{'I perhaps should have been bolder}

\section{when trying to juggle shift times to avoid}

\section{standing in shopping queues; there}

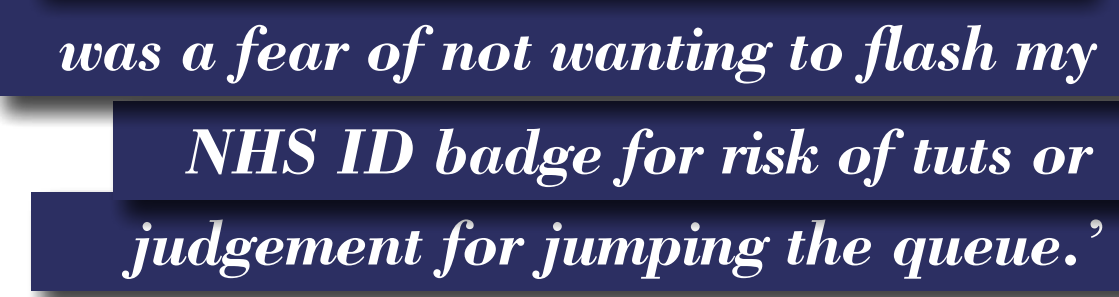

also sacrifice time with them for the greater good. This is something quite difficult to describe but during the time of need it was not often questioned; patient centred-care is so ingrained into our dental backgrounds and the fight against COVID-19 was so strong.

\section{Smiling with my eyes}

As DCPs, we are used to appreciating that communication is key. Although wearing a mask is not new to us in the dental field, one of the hardest aspects of this period that I feel I struggled to come to terms with was having a mask on pretty much all of the time. Not being able to take the mask off to offer a friendly smile still to this day does not feel right and was especially tough with poorly patients, when I wanted to offer a friendly face in a time of need or to comfort a struggling colleague. I have learnt now to smile with my eyes.

I have been humbled at the outcry of public support. I have felt embarrassed that environment but having to go into the environment of others has certainly been an eye-opener. I thoroughly enjoyed being part of this ever-evolving service and being out and about in the community. I felt sad when this aspect of redeployment came to an end but this was a positive in that it reflected that numbers of cases were dropping or being managed.

\section{Administering vaccines}

I am used to working with patient group directives as a DHT when administering local anaesthetics during an inferior dental block or infiltration, for example, but more recently I have become accustomed to using them to administer COVID-19 vaccinations. Injecting into the arm is very different from the mouth but the factor I have thought about most is the unknown, the complete opposite of what we are taught to strive for as best practice as DCPs. I felt much sympathy when having to reassure a patient apprehensive about having the 


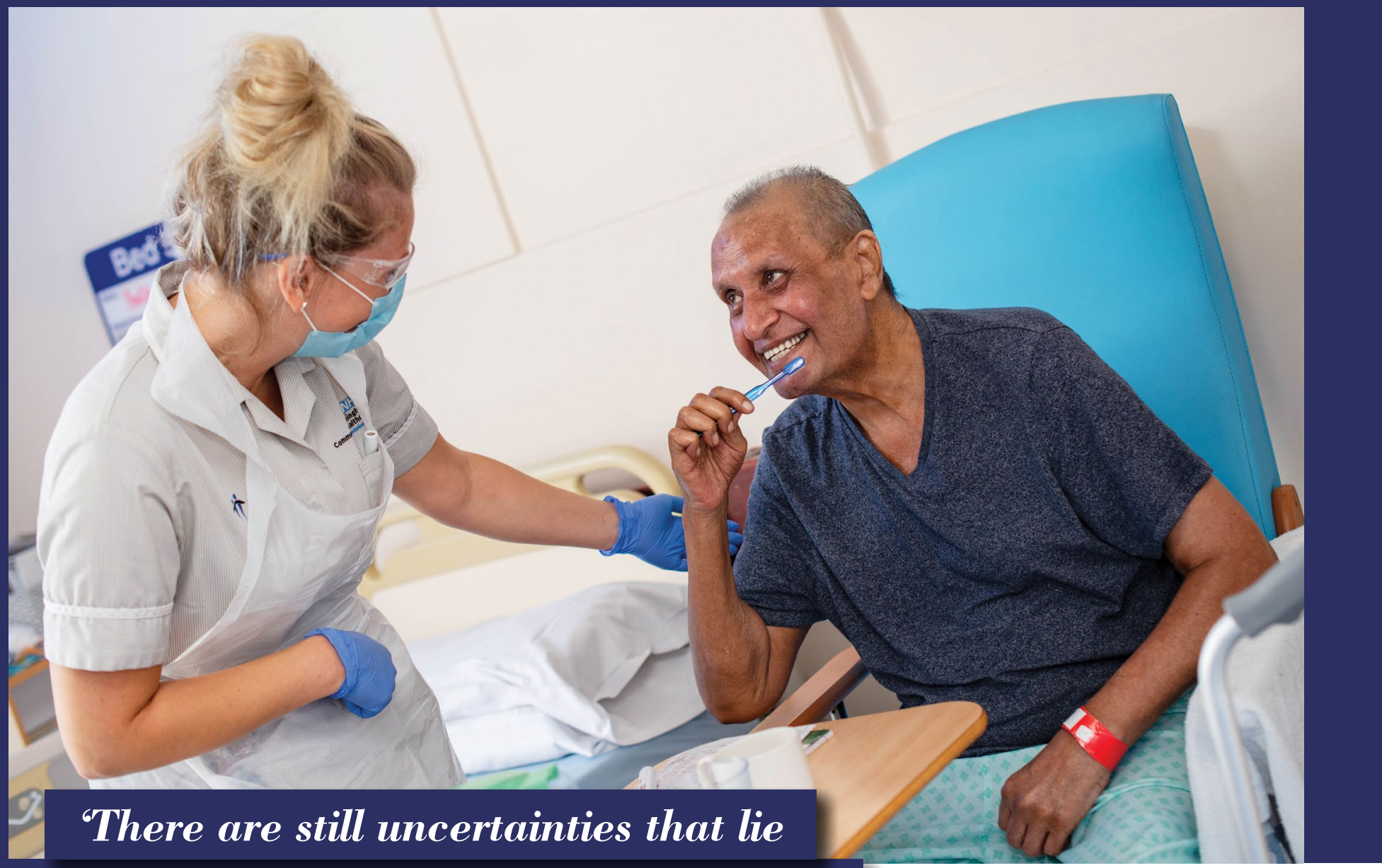

\section{ahead. Will I always feel like a bee keeper}

\section{in a hood? Will I see the colleagues}

\section{again with whom some of the most difficult times were shared?'}

COVID-19 vaccine, but felt the same concerns waiting to have mine. 'Winging it' is not a term we would usually use in our evidence-based world of professionalism and standards but, to be honest, it did feel at times like we were flying by the seat of our scrubs - but ultimately always doing the right thing by the patient. I have certainly discovered a new sense of humour and light-heartedness about life!

Redeployment of the dental team is just one example of where existing skills have given rise to a whole host of additional ones. The pandemic and its challenges have broadened my scope of practice and I have learnt so much along the way. We are so capable. This is just a snapshot of life during the pandemic and I know I am not alone and many will have different experiences. We as a profession have been put to the test over the last 12 months in many ways. The pandemic has given new insight and meaning into the words and skills we associate with as dental professionals and individuals.

\section{Mixed emotions}

The pandemic has been exhausting and it has raised a mixture of emotions but out of the dark there is always light. I'm glad to say that it is now coming from overhead on the dental chair again! The prospect of sitting inches away from a patient's face when the whole world is being advised to socially distance is still overwhelming if dwelled upon for long enough. There are still uncertainties that lie ahead. Will I always feel like a bee keeper in a hood? Will I see the colleagues again with whom some of the most difficult times were shared? What about our own patients and how have they managed during lockdowns? What about the backlog of treatment? What will we learn from the pandemic? Will we embrace the changes or sit on the edge of the sofa again awaiting the next announcement from some authority or other?

Once this is 'over', hopefully we will get chance to sit back and reflect. Some things may have changed forever but there is always the opportunity to learn and grow. Change is sometimes for the best although it is not always easy to accept. Despite the struggles, there have been positives to come out of the pandemic and when we get the opportunity to debrief we may come to embrace and share some of the new ways of working and engaging with patients, the public and colleagues.

As stressful as work can be, work has been a lifeline during this time (despite being under cover of sweltering PPE during lovely sunny days!) and I am grateful for the life lessons. We are all only human and must show compassion to ourselves from time to time. Being happy and being able to have a laugh is just as important as being professional, which can sometimes get lost in the hubbub of working life.

I will be reassessing my work-life balance as I have come to realise what is truly important to me. Recent experience has taught me to look for light in the darkest day; life is for living and there is pleasure in the simplest of things. So no matter what you have been up to, or what your personal experiences have been, well done! We have come this far and are braced for whatever the future may hold.

https://doi.org/10.1038/s41407-021-0621-0 